\title{
Detection of old scattered windthrow using low cost resources. The case of Storm Xynthia in the Vosges Mountains, 28 February 2010
}

https://doi.org/10.1515/geo-2019-0040

Received Sep 02, 2018; accepted May 29, 2019

\begin{abstract}
Unlike the contiguous windthrows, the scattered windthrows occurring as a result of wind gusts of lower speed $(100-140 \mathrm{~km} / \mathrm{h})$ than in the first case $(>140 \mathrm{~km} / \mathrm{h})$ are much more difficult to detect due to their much smaller areas and due to their very large number (several hundred in the wooded Vosges Mountains). The objective of this research is to present a rapid procedure for the detection of the scattered windthrows based on low cost, Landsat type images, knowing that certain sensors cannot be accessed without significant investments. Our application is based on the study of effects caused by the Storm Xynthia in the Vosges Mountains in the North-East of France, on 28 February 2010. Thus, based on two sets of Landsat satellite images, we used the "dark object" approach and the Disturbance Index, as well as the image classification before and after the storm, resulting in a map of changes. Following the detection process, 257 scattered polygons were detected, totalling 229 ha. For validation purposes, highresolution images and orthophotoplans taken before and after storm were used. The error matrix was calculated, achieving an overall accuracy of $86 \%$, which confirmed the quality of our analysis and supported this procedure for detecting scattered windthrow based on low cost resources.
\end{abstract}

Keywords: change detection; thematic information extraction; windthrow; France

\footnotetext{
*Corresponding Author: Paula Roxana Furtuna: FURTUNA Babes-Bolyai University of Cluj-Napoca, Faculty of Geography, 5-7 Clinicilor Street, 400006 Cluj Napoca, Romania; Email: paula_roxana.furtuna@yahoo.com

Ionel Haidu: University of Lorraine Laboratory LOTERR-EA7304, Campus Ile du Saulcy, Building C, 57045 Metz Cedex 01, France; Email: ionel.haidu@univ-lorraine.fr

ORCID: 0000-0003-2586-7068

Sébastien Lebaut: University of Lorraine Laboratory LOTERR-EA 7304 Campus Ile du Saulcy, Building C 57045 Metz Cedex 01, France
}

əopen Access. ๑ 2019 autor, published by De Gruyter.

(cc) BY

\section{Introduction}

Windthrows are known to depend on the stability of the stands in relation to wind speed and force, stand composition and structure, trees height and their state of health, the soil type and the morphometric and morphological characteristics of the relief. Despite of these risk factors, the decisive cause of windthrows is given by the wind gusts speed. Of course, the cyclones, generating the most destructive winds, are not known at the latitudes of France. However, violent storms happen regularly in northern Europe. From a meteorological point of view, the storm is the active center of a depression that is associated with strong wind gusts and high intensity precipitations. Some storms, that affect French territory, come from the shifting of a tropical cyclone into a depression of medium latitudes. Storms are known to be the most destructive natural disasters for forests in terms of frequency of occurrence, damages caused and their spatial extent [1-3]. Unfortunately, there is no time series archive long enough to shape their frequency. But due to the existence of satellite imagery archives, it is possible to reconstitute the windthrows caused by the latest storms.

Such storm occurring in France was the Storm Xynthia, on 28 February 2010. Although it did not have the exceptional nature of the catastrophic storm Lothar in 1999 [4, 5] or storm Klaus in 2009 [6] by its maximum speed (160 $\mathrm{km} / \mathrm{h}$ ), it caused major damage i.e. thousands of cubic meters of forest destroyed in Lorraine and Alsace. The Pôle interrégional de la Santé des Forêts du Nord-Est Institute $[7,8]$ mentions for the Lorraine region some $15,000 \mathrm{~m}^{3}$ of destabilized spruce at Louppy-sur-Loison (department of Meuse), some pine forests in the Warndt Plateau (department of Moselle), and, to a lesser extent, some aged beech forests. In the Alsace region, the same source [8] mentions some limited destabilization in forest border areas or in areas where there is no longer any interest in logging. Besides the official reports [9-12] the press of the time, i.e. The Vosges Matin newspaper, LOR'Actu, France Culture, but also other local and regional media sources

This work is licensed under the Creative Commons Attribution 4.0 License 
have presented more dramatically the effects of this storm on the forests of Vosges mountains, suggesting that many more points would have been affected, as the windthrow had a diffuse character [13, 14]. Even if several years have passed since that event, through remote sensing images that stored the condition of vegetation, in this paper we tried to identify the scattered affected areas that might be ignored due to their small extension, but they were important from the economic point of view.

The detection of the changes caused by storms, be they contiguous or scattered, is very important in order to establish spatial and temporal trends in the rehabilitation and management of forest resources. Papaik and Canham [15] show that storms can be seen as an integral part of the forest ecosystems functioning, but that the detection of changes must be conducted in order to know and manage ecosystems and forest resources. The use of remote sensing in forestry applications is today an extremely useful tool to acquire knowledge and conduct the management of forest ecosystems. The information provided by this tool on the interaction between the atmosphere and the forest for the purpose, for example, of locating the damage caused by storms in the context of climate change [16-19] or for carbon sequestration potential $[20,21]$ is a must because it can help extrapolate this information to larger spatial scales.

Huang et al. [22] proposed a method for the detection of forest areas affected by storms, the use of vegetation indices and the Tasselled Cap Transformation. Based on this transformation, Healey et al. [23] developed the Disturbance Index, used for windthrow detection. This procedure was then optimized and adapted to the purpose of continuous monitoring of forest disturbances through time series images [24-28].

Another trend for the development of remote sensing to identify windthrow refers to semi-automatic or automatic procedures. Stach et al. [29] proposed mapping by optical and radar remote sensing. Huang et al. [30] developed dark object concept and support vector machines to automate forest cover change analysis, while Kennedy et al. [31] used LandTrendr segmentation algorithms in order to develop maps of forest disturbance and regrowth.

Regarding the methodology applied to assess the consequences of storms Martin and Lothar in 1999 on the forests of France, Stach et al. [32] concluded that the best results were those achieved by radar remote sensing.

Due to the meteorological risk events causing significant damage throughout recent decades, France, but also other countries in Western Europe experienced windthrow over large areas. Therefore, the researchers from the French National Forest Inventory $[6,33]$ have developed a new semi-automatic methodology, the "7-points method" to map the damage caused by the storms and to monitor the land use adapted to varied landform conditions. The principle of the method is based on the "pixel per pixel" comparison of two satellite images recorded before and after the storm. The "pixel per pixel" and "spectral band with spectral band" difference is performed to highlight the radiometric evolution between the images before and after the storm. In order to detect the windthrows, the "7-points method" combines the change detection techniques with an automatic image segmentation phase, namely the delimitation of homogeneous areas in terms of radiometry and texture. This methodology has been used to map the windthrows and damage caused by the storms Lothar and Martin in 1999 in Forêt des Landes, South-Western France. The windthrow mapping in the Vosges department in the year 2002 was carried out by combining remote sensing for the plain and hill areas with aerial photogrammetry for the mountain areas [33]. The forest damage caused by the storm Klaus occurring in January 2009 were also evaluated using the 7-points method [6]. The working principle of these methods is the achievement of real-time information by transforming the remote sensing images into vegetation state indices needed to identify the disturbances or abnormalities occurring in the forest areas [34].

The wider and wider use of very high-resolution (VHR) remotely sensed images has stimulated the development of object-based methods and data mining techniques, which were much more effective for change detection [35]. Bauman et al. [24] have developed a methodology for detecting and analysing windthrow for various meteorological phenomena (from simple storms to meteorological extreme events). Moreover, they have managed to separate the disturbances due to the storms as compared to those caused by massive forest cuttings in the forest areas, as well as to the other land cover classes. The methodology applied in this study was based on the windthrow detection using the Disturbance Index that was designed considering the Tasselled Cap Transformation and the "dark object" approach.

The purpose of our application is to detect the forest areas in the Vosges Mountains affected by the Storm Xynthia in February 2010, as it is well known that there are scattered windthrows, without taking into account more sophisticated and more expensive imaging resources, such as those mentioned above, but, on the contrary, using Landsat's least expensive satellite imagery. 


\section{The Study Area and the Storm Event}

The study area is represented by the Vosges Mountains $\left(7,360 \mathrm{~km}^{2}\right.$, of which $4,400 \mathrm{~km}^{2}$ are covered by forest), located in the North-Eastern part of France (see Figure 1), in low altitude mountains with the maximum altitude of $1,424 \mathrm{~m}$, in the Grand Ballon Peak. The mountains expand longitudinally over approximately $200 \mathrm{~km}$ until the German border, along the west bank of the Rhine River. Their maximum width is $60 \mathrm{~km}$ in the South, $20 \mathrm{~km}$ in the North and only $4 \mathrm{~km}$ in their upper third part.

The Vosges Mountains are predominantly covered with forest $(60 \%$ of the surface of the mountains today), especially conifers (pine and spruce), going up to the altitude of $800-1000 \mathrm{~m}$, while towards the foothills of the mountains there is a transition to deciduous forests, as well as to open meadows that were created by man for agricultural practices. The forest cover of the Vosges Mountains ranks second in France in terms of extent, after the Landes forest. The Vosges forest is the first region of France in terms of pine, fir and spruce production, with a crop of 1.5 million $\mathrm{m}^{3}$ of logs, namely $1 / 3$ of the country's total production. Nowadays, the authorities apply the sustainable management principle, so that despite the significant harvest, the forest of Vosges is progressing, the annual harvest being much lower than the growth rate [6].

Due to the geographic location, the Vosges Mountains experience two climate influences: oceanic and semicontinental. Because of this location, climatic conditions and topography, the Vosges Mountains area has often been affected by major winter storms that have led to windthrows over extensive forest areas, causing the greatest damage if we also referred to other damaging causes for forests.

The Xynthia winter storm occurred from a low pressure system formed in the subtropical area South of the Azores on 25 February 2010. The Southern flow of cold air masses from the altitude caused the formation of a depression over the Centre and Eastern part of the North Atlantic Ocean. The high temperature difference between the extremely hot air flow above the Africa and the cold air in the Eastern Atlantic Ocean has accentuated the decrease in atmospheric pressure that led to the formation of the powerful Xynthia cyclone. The cyclone experienced a rapid intensification affecting 8 countries, and causing 65 deaths [36] in its movement from SW to NE (see Figure 2).

As Bock et al. [37] stated, the institutes in France involved in the management of the forest resources Office National des Foręts (ONF), Institut pour le Développe-

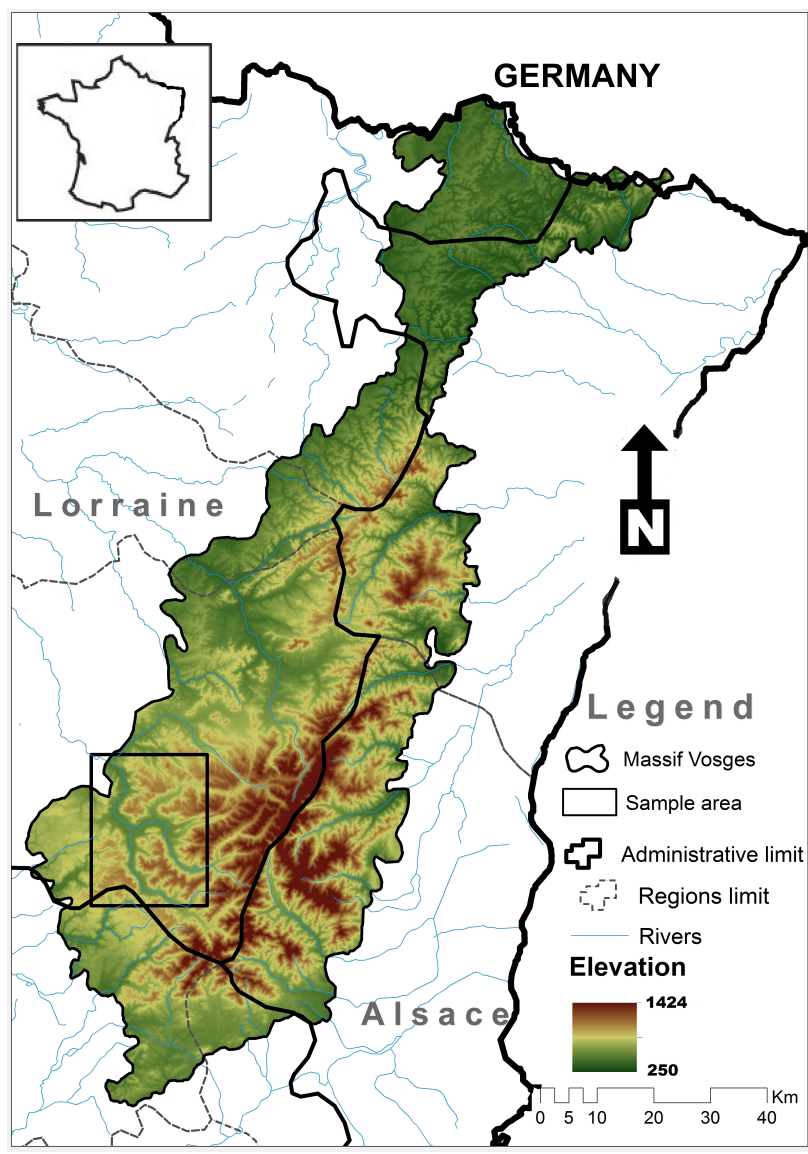

Figure 1: Location of Vosges Mountains and a sample area highlighted later

ment Forestier (IDF) and the Institut National pour la Recherche Agronomique (INRA), have studied the dependence between windthrows and wind speed. In regular beech forests, isolated windthrows occur at a wind speed ranging between 100 and $120 \mathrm{~km} / \mathrm{h}$, multiple scattered windthrows occur at a $120-140 \mathrm{~km} / \mathrm{h}$ wind speed, and large scale and frequent windthrows occur at speeds over 140 $\mathrm{km} / \mathrm{h}$. The same authors also found that at the height of the trees below 23-24 $\mathrm{m}$ the windthrows were rarer, but at wind speeds over $120 \mathrm{~km} / \mathrm{h}$ the frequency of windthrows increased proportionally to the height of trees.

\section{The Alternative of Using Low Cost Resources}

Nowadays, in the context of the impetuous development of remote sensing techniques, there is a natural preference for high and very-high-resolution (VHR) remote sensing images. 


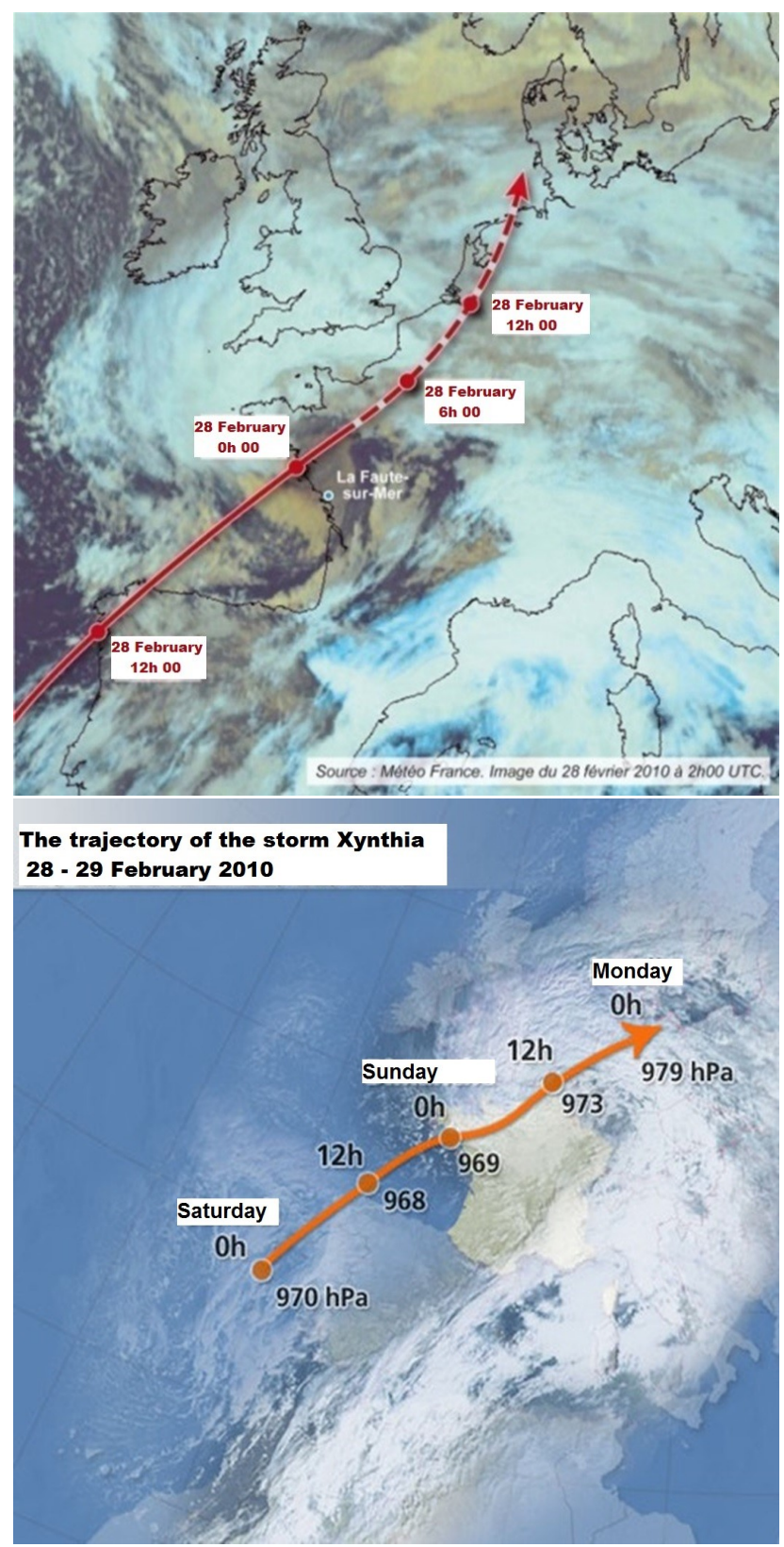

Figure 2: The trajectory of the Xynthia storm, (source [38])

The availability of satellite data varies and choosing the best sensor is very important in order to select the data which better suit our purpose and to get more accurate results. When detecting windthrows using optical satellite imagery it is important to know which sensor is appropriate. Schwarz et al., [39] summarized the criteria to be considered in choosing the appropriate sensor, namely: data availability, spectral resolution, spatial resolution and temporal resolution. Besides availability and resolution, the cost of data represents also an important factor to be considered. We also have to admit that sometimes it is not pos- sible to capture real-time images or create time series of images. Maybe this would be possible, but the cost of raw data purchases is too high. Therefore, we would like to assess if less expensive and easier-to-acquire images, such as Landsat, despite their lower resolution, would still be sufficient and capable of detecting scattered windthrows. Starting with 2014 Sentinel Radar images are also free, but obviously these cannot be considered because the event we studied occurred in 2010. If the purpose of a research is the restoration of the old windthrown trees, obviously, only the sources produced by the older satellites or having an archive (Landsat from 1980) can be accessed [40-47].

The reason in choosing Landsat sensor for this study was the wide swath and the low cost. The medium resolution Landsat data is not as sharp as high-resolution images, but the amount of information it contains along with the large area coverage make this data suitable for large- or small-scale studies.

We studied the scattered windthrows in the Vosges Mountains and the exact location of these disturbances was unknown. Each type of satellite images has advantages and disadvantages in detecting windthrows. Malthus et al. [48] have developed a comparative study to emphasize the advantages, limitations and, where possible, even prices of current remote sensing image sources used in commercial forestry. Similar comparisons have been developed by Suárez et al. [49], which compared optical techniques with RADAR and LIDAR data. Melesse et al. [50] presented the characteristics of 20 different satellite sensors, while Einzmann et al. [3] summarized the specification of sensors used for forest disturbance detection.

The free access policy for Landsat data has made this data more and more frequently used in remote sensing studies [51, 52]. However, with the accessibility of these data, there is a challenge to find images without clouds or with very little cloud coverage in the analyzed area, because clouds can significantly influence the reflection from different spectral bands [53]. This is an issue we have also faced, and we will present next how we have solved this shortcoming.

\section{Materials and Methods}

\subsection{Workflow}

In this study we aimed to highlight the applicability and efficiency of Landsat data in detecting scattered windthrows caused by the storm Xynthia that crossed the Vosges Moun- 


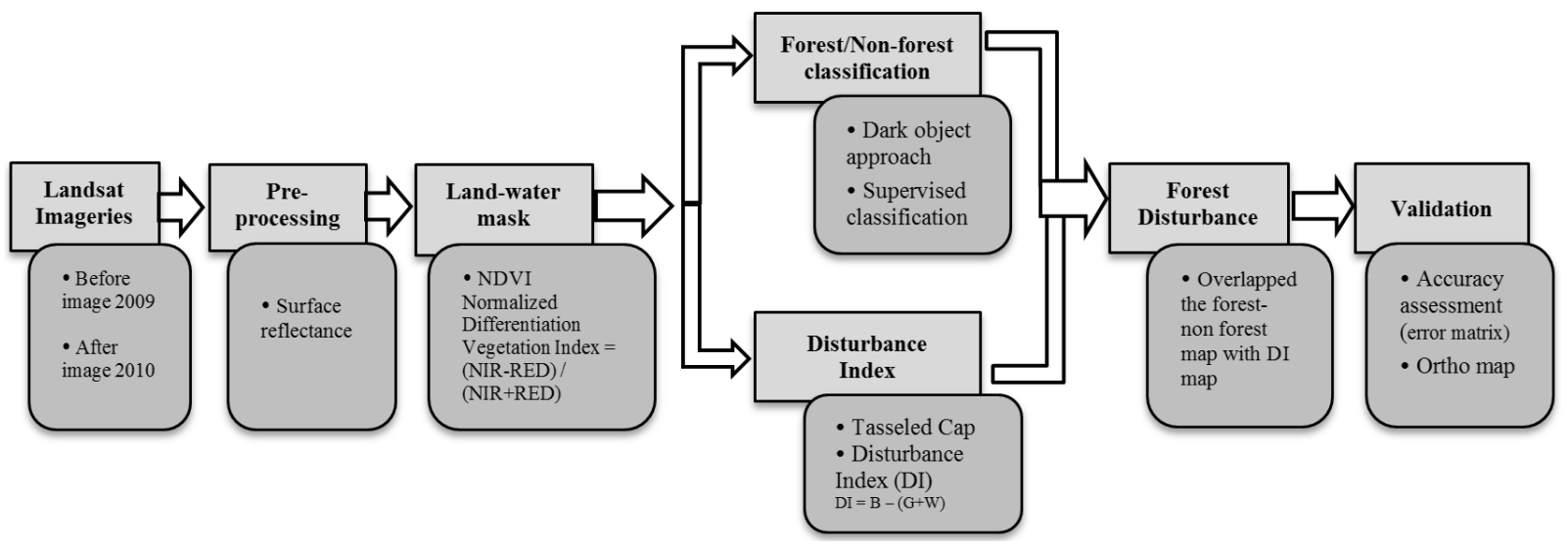

Figure 3: Methodological steps

Table 1: The characteristics of images that were used for the Vosges Mountains area

\begin{tabular}{ccccc}
\hline Date of the Xynthia storm & Path/Row & Lat/Long & Before Xynthia & After Xynthia \\
\hline $27-28.02 .2010$ & $196 / 026-027$ & $48.9 / 6.9$ & 17.06 .2009 & 4.06 .2010 \\
\hline
\end{tabular}

tains on 28 February 2010. The images were downloaded freely from the USGS site [54]. Thereby, a multi-temporal set of Landsat 5 TM images (with 7 spectral bands - $30 \mathrm{~m}$ spatial resolution) was used. The images were acquired on different days 17.06.2009, before the Storm Xynthia, and on 4.06.2010, after the storm (Table 1). We selected no clouds or very few clouds images that were recorded during the growing season and for the same vegetation season (June), to reduce the impact of vegetation in different seasons.

The study was conducted using standard ArcGIS and ENVI software's. The main steps followed are illustrated in Figure 3.

The first step consists in pre-processing the satellite imagery, namely converting them from digital numbers (DNs) into reflectance. This operation was done using the formulas given by Chander \& Markham [55, 56]. First, the DNs were converted into spectral radiance using the equation:

$$
\mathrm{L} \lambda=(\text { gain } * \mathrm{DN})+\text { bias } \lambda
$$

where: $\mathrm{L}_{\lambda}$ - the spectral radiance at the sensor level and referring to the wavelength $\lambda$ for the specific band; $D N$ Digital Number; gain and bias - are specific calibration parameters determined before launch

For the relatively clear Landsat images, a reduction in variability of images has been made by converting spectral radiance into surface reflectance, using the following equation:

$$
\mathrm{R} \lambda=\left(\pi^{\star} \mathrm{L} \lambda{ }^{\star} \mathrm{d} 2\right) /\left(\operatorname{ESUN} \lambda{ }^{\star} \sin \theta \mathrm{S}\right)
$$

where: $\mathrm{R} \_\lambda$ - Spectral radiance at the sensor's aperture; $\mathrm{L} \lambda$ - Spectral radiance at the sensor's aperture calculated through equation 3; d - Earth-Sun distance [astronomical units]; ESUN $\lambda$ - Mean exoatmospheric solar irradiance [56]; $\operatorname{Sin} \theta S$ - solar zenith angle in degrees.

The next step consists in masking the water bodies and dark soil and clouds to avoid these pixels being confused with pixels corresponding to the vegetation areas, by using the Normalized Differentiation Vegetation Index (NDVI) values. These non-forest dark surfaces such as water, dark soil, and dark impervious surfaces need to be masked because these can be as dark as or even darker than forest pixels [26]. To identify and remove these pixels we used the method proposed by Huang et al. [26], which was based on the spectral properties of water bodies, dark soil and clouds. Pixels are classified as water or dark soil if they have reduced reflection in the short-wave infrared (SWIR band) and if they have low NDVI index values calculated based on the spectral bands in the visible (RED) and near-infrared (NIR). After calculating the NDVI, a threshold was set to delineate the land-cover classes from the masked areas covered by water and soil, respectively. In this study the 0.25 threshold was used.

Then the images were grouped into forest and nonforest areas. The classification was made for the two images, before and after the storm, respectively. Then, the difference between the grouped images was made, leading to the identification of lost forest vegetation areas. In addition, to improve the result obtained in the previous step, the Disturbance Index (DI) was used. 


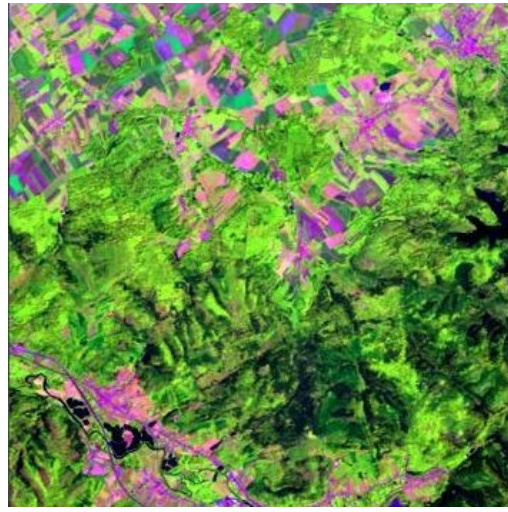

(a) satellite image in 5-4-3 combination

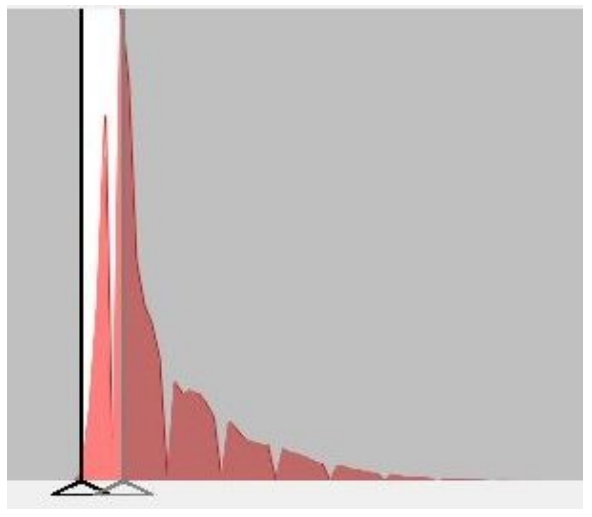

(b) delineation of "forest peak" using RED band histogram

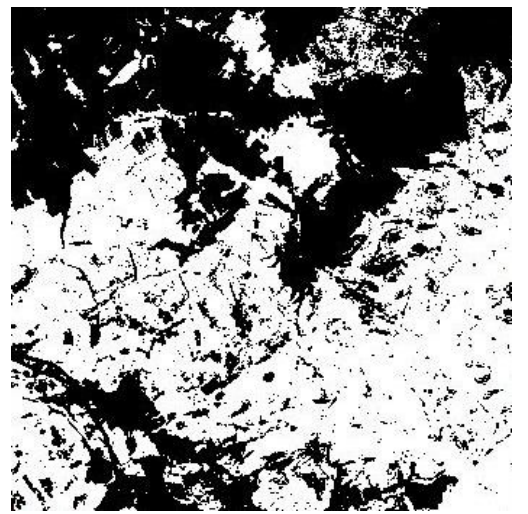

(c) forest pixels (white) after applying the 0.25 threshold

Figure 4: The procedure for the delineation of forest pixels based on the histogram for the local image window, (adapted after Huang $e t$ al. [30])

Then, the validation of results was carried out. The evaluation of results relies upon the data and information used. The accuracy can be directly influenced by the quality and availability of the ground data (the resolution of aerial orthophotos, high-resolution satellite imagery). The first step in results validation is to calculate the accuracy assessment and the Kappa statistic. To evaluate the accuracy of the supervised classification, we used 100 random points for each class we used. These points were manually labeled using Quickbird Google Earth and RapidEye high-resolution imagery [57]. These high-resolution images were used only for the confirmation and validation of the classification. Also, for results verification and validation purposes, orthophotoplans from 2009 were used, with a resolution of 2.5 and $5 \mathrm{~m}$, available in [58].

\subsection{Training and image classification}

In order to obtain the forest areas, the image before the Storm Xynthia must be classified into "forest" and "nonforest". This is carried out following two steps: automatic extraction of forest pixels based on the histogram, and by conducting a supervised classification of the two images before and after the occurrence of the phenomenon.

\subsubsection{Automatic extraction of forest pixels}

The forest pixels have been identified using the "dark object" approach [30] which involves the delineation of the "forest peak", based on a band local histogram (see Fig ure 4). In the absence of non-vegetated dark objects (which were masked previously), the forest pixels will be located to the left of the histogram, while the first peak on the left will be considered the "peak forest".

Huang et al. [30] recommend considering two major factors:

i) delineation should be done for a local image window because this area will contain fewer classes of land cover and the delineation of forest classes from other classes will be easier to achieve.

ii) selection should be made of the appropriate band to create the histogram which sets the basis for class delineation.

In order to determine whether pixels have been classified properly into forest and non-forest, we have set samples of black pixels representing vegetation based on which we calculated the Integrated Forest Index (IFI) [24, 30].

$$
I F I=\sqrt{\frac{1}{N B} \sum_{i=1}^{N B}\left(\frac{b_{p i}-\bar{b}_{i}}{S D_{i}}\right)^{2}}
$$

where: $\bar{b}_{i}$ and $S D_{i}$ are the mean and standard deviation of forest training pixels within the image for band $I ; b_{p i}$ is the band $i$ spectral value for pixel $p$; $N B$ is the number of spectral bands.

Low IFIs values indicate a high probability of wooded areas, while high values indicate high probability of other land cover categories. Certain dark pixels corresponding to crops may be spectrally similar to pixels for forest areas but will have IFIs values lower than the forest areas. To eliminate them, it is necessary to set a threshold value, which separates the forest areas from the other areas. For the present study, the threshold was set to 3 , so pixels smaller 


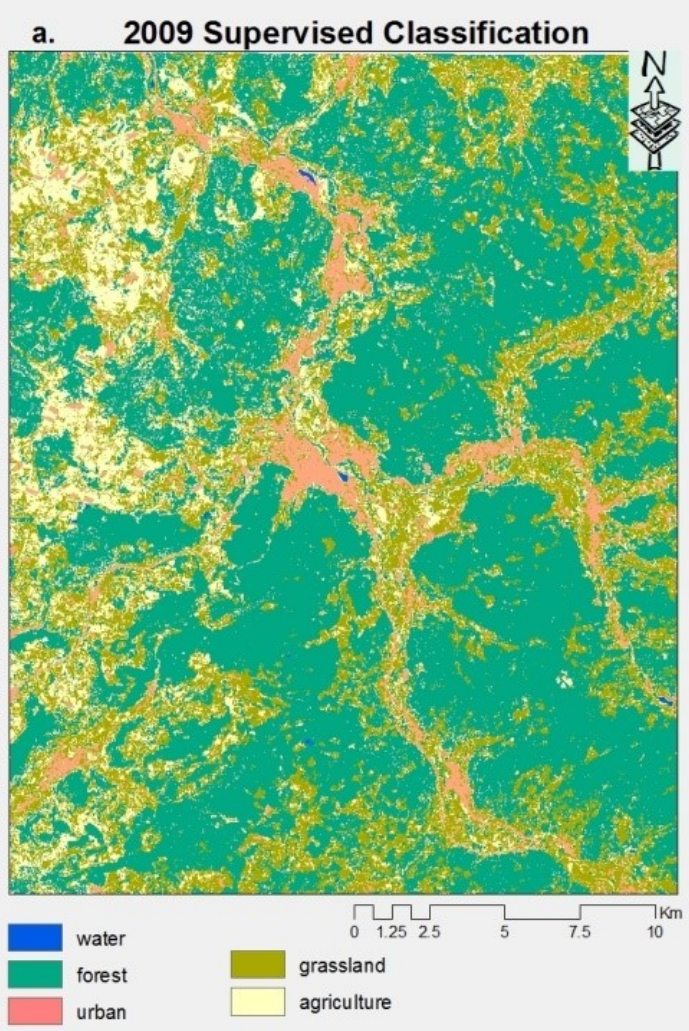

b.

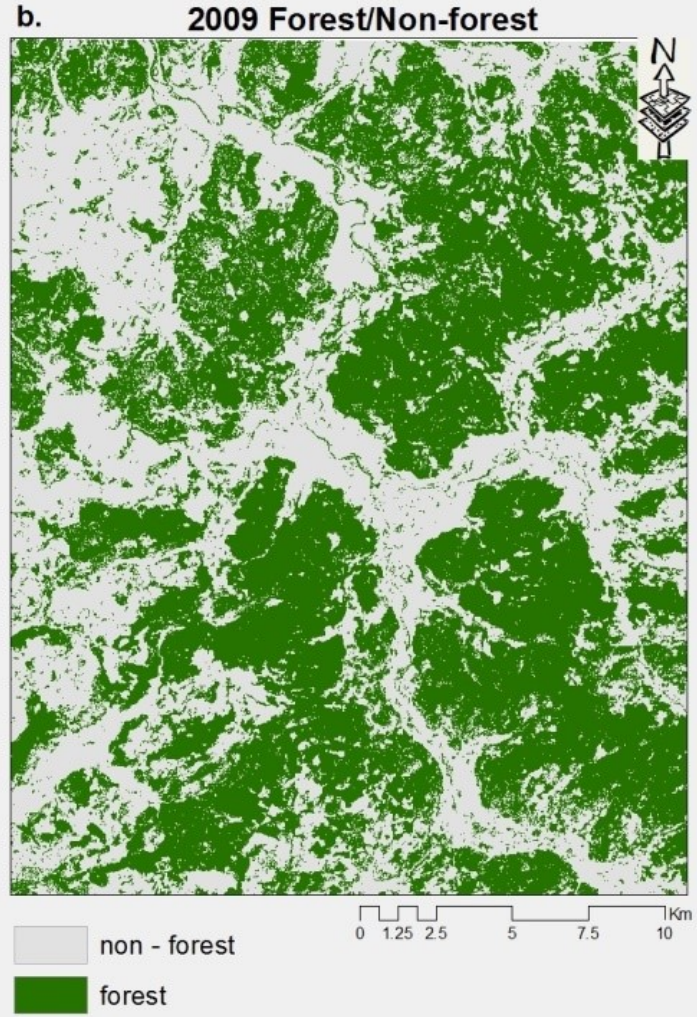

Figure 5: Supervised classification (a) and forest/non-forest classification (b) than or equal to 3 were considered to belong to the wooded areas.

\subsubsection{Supervised classification}

The purpose of the classification in this study is to complement the result of extracting forest pixels by means of the histogram. First of all, land cover classes [water bodies, forest areas (conifers, mixed and deciduous trees), urban areas, pastures and agricultural areas] were established and the pixels were selected for the classification algorithm to acknowledge the classes. A number of 150 training samples were used for each land cover classes selected. After running the Maximum Likelihood Classification algorithm (in Figure 5a), the resulting images have been reclassified into forest areas and non-forest areas. Finally, following the classification of both images from 2009 and 2010, the separation of the forest areas from the non-forest areas was achieved (see Figure 5b). This will be used in the end to obtain a change map for the two analysed temporal frames.

To exemplify the result, we performed a zoom on a 26.6 $\mathrm{km} \times 20.5 \mathrm{~km}$ sample area, i.e. on a 54,613 ha area, with the Remiremont city at the centre a sample that was also used for the other examples.

\subsection{Forest Disturbance Detection}

The detection of forest disturbed areas was carried out using the Disturbance Index (DI) developed by Healey et al. [23] and applied by [24, 59-65, 65]. The procedure is based on a combination of bands resulting from the Tasselled Cap Transformation, which reduces the six bands of Landsat TM image (excluding the thermal band) into three bands that render brightness (B), greenness $(\mathrm{G})$, and wetness (W).

This index highlights the difference in spectral signatures and thus disturbed forest areas have higher brightness values and lower values for greenness and wetness bands compared to undisturbed forest areas. The index is calculated based on the formula:

$$
\mathrm{DI}=\mathrm{Br}-(\mathrm{Gr}+\mathrm{Wr})
$$

where: $\mathrm{Br}, \mathrm{Gr}, \mathrm{Wr}$ are the Tasselled Cap bands, standardized (resized) around the scene's mean forest value.

The result of the calculation is a single band, where positive values generally indicate areas with disturbance. In order to separate the disturbed areas from the nondisturbed ones, it is necessary to identify a limit threshold, depending on the environmental conditions in the studied 
area. In our case, the value of $\mathrm{DI}=2.5$ best identifies the areas affected by windthrows.

\section{Results and Discussion}

The algorithm we propose is similar to the French methodology known as the "7-point method" [33]. However, this still includes different stages, proving to be effective in detecting scattered windthrows based on Landsat images.

The difference between this method and the "7-points" method is given by the steps followed and the approaches used. The first difference is given by the satellite images utilized. This study is based on medium-resolution Landsat satellite images, while the "7-points" method uses high resolution images. In the "7-points" method, "pixel per pixel" is used in order to detect the changes. The same "pixel per pixel" approach was also used in this study, but it was applied to forest/non-forest images. The next stage in the "7-points" approach consisted in the segmentation of the disturbed areas. As Darwish et al. [66] stated, the segmentation techniques on the Landsat images emphasized the fact that the results provided a low accuracy. Therefore, this method is not recommended for medium resolution images. Instead, in this study we used the Disturbance Index to detect the affected areas.

The last step in the "7-points method" is to integrate the results obtained by segmentation with the soil results. Thus, by classifying the disturbances produced, a map of damage was obtained. Due to lack of ground data, we have chosen to do a validation based on the error matrix.

The Landsat images have been used successfully in other studies to detect forest area affected by wind storms using vegetation indices, image differencing, principal component analysis and others approaches. Landsat data and Disturbance Index was used by Healey [23] in assessing forest disturbances in multi-temporal data. Vogelman, [67] used Landsat time series data sets to detect forest changes. Furtuna et al., [68] used Tasseled Cap Transformation based on Landsat satellite to detect a windthrow occurred in 2011 in Apuseni Mountains. Another study by Vorovencii, [69] stated that applying image differencing in Tasseled Cap Transformation (based on Landsat image) is the most appropriate technique to detect windthrows.

After running all the steps to detect the damage areas, the last step involved the overlapping of the initial image classified as "forest areas" and "non-forest areas" with the map derived from the DI calculation, and so we obtained a change map for the forest area in the Vosges Mountains in 2009-2010.

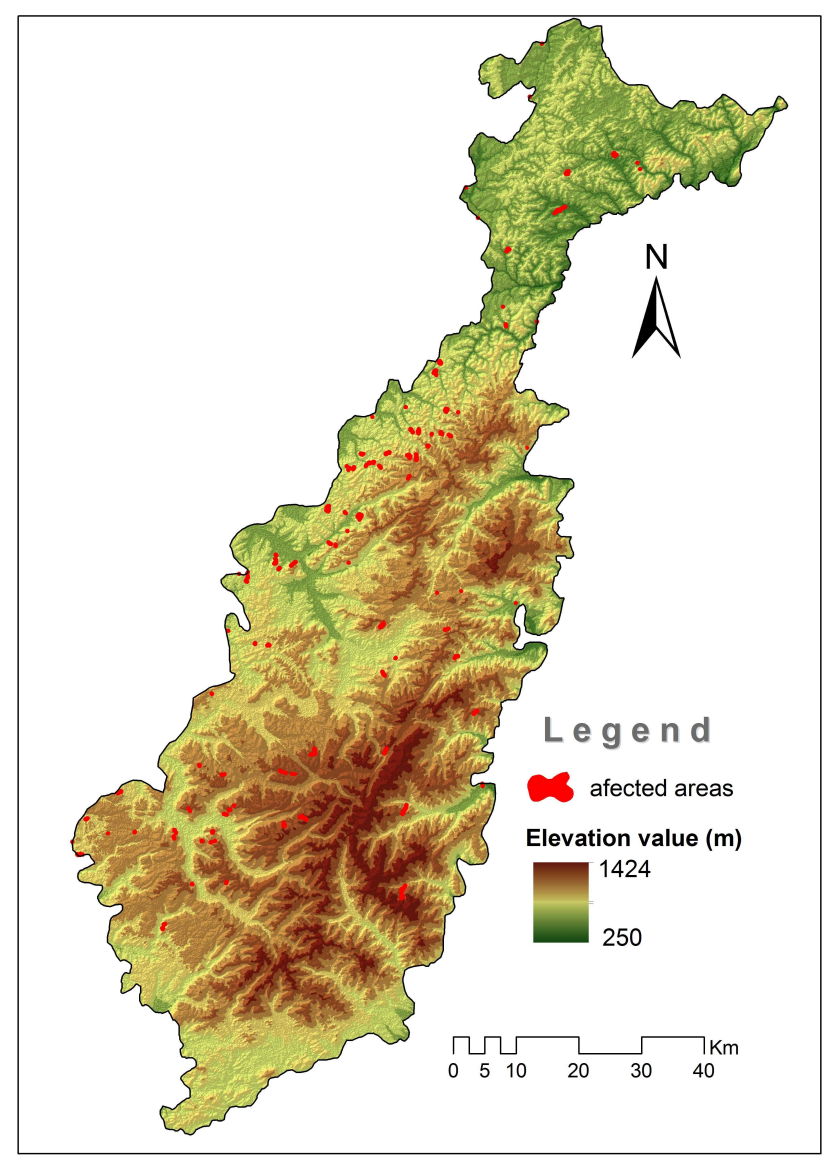

Figure 6: Areas affected by diffuse windthrow

As seen in Figure 6, scattered windthrows occur in the form of scattered polygons, or rather points, on the territory of the Vosges Mountains, some points being so small that they cannot be visually perceived at the scale of cartographic representation in the figure above. We identified 257 polygons affected by windthrows, with a total area of 229 ha. We attach supplemental material to indicate scattered windthrow (see Appendix A).

\subsection{Accuracy Assessment}

To evaluate the quality of the analysis, we assessed the overall accuracy and the Kappa coefficient. Following the classification of the two images, the accuracy assessment was carried out in two steps: a) the accuracy of supervised classification and of forest/non-forest classification and $b$ ) the accuracy of the forest-change map.

The polygons resulting from the detection process were overlapped with the aerial orthophotos to see whether there is vegetation in the detected areas. The outcomes were summarized in an error matrix, while cal- 


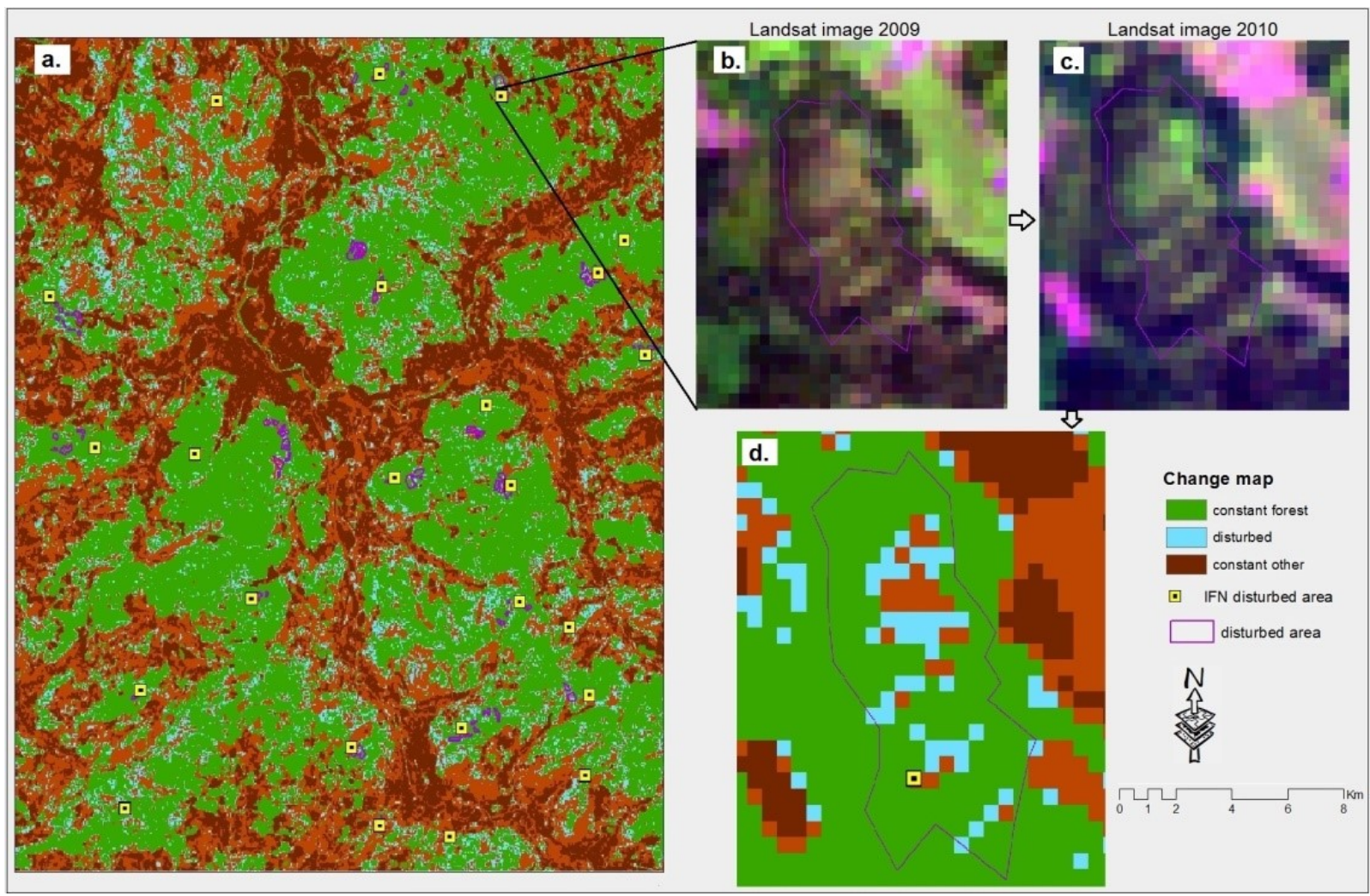

Figure 7: Forest change map (a) overlapped with the polygons resulting from the detection process, as well as the points where windthrows occurred in 2010 (according to INF): one polygon overlapped with the 2009 satellite image (b), and the 2010, respectively (c), and a zoom on the same polygon (d)

culating the overall accuracy and the Kappa coefficient. Therefore, the accuracy assessment calculated for the forest/non-forest classification is given by the overall accuracy $=94.14 \%$ and by the Kappa coefficient $=0.92$. The evaluation of the forest changes occurred between 2009 and 2010 was carried out based on a sample of 300 points. The previously defined samples considered as real elements in the field were used to calculate the error matrix, the overall accuracy, the kappa statistic and the user's and producer's accuracy for each class.

For the change map we used three classes, namely constant forest (CF) that did not change in the two images, disturbed areas (D) and other non-forest classes (NF). The constant forest area is given by those areas that were represented by forest both in the before Storm Xynthia image and in the after Xynthia image, while the areas with disturbances are those areas that were classified as forest in the before Xynthia image and that appeared as non-forest in the after Xynthia image. The overall accuracy obtained for the change map was high, i.e. $86 \%$, and the value of the Kappa coefficient was 0.84 . Also, the class represented by the constant forest had the user's and producer's accuracy higher than the disturbance class. The error matrix was cal- culated, achieving an overall accuracy of $86 \%$, which revealed that our methodology adapted for low cost image resources, could be used for the rapid detection of scattered windthrows in the temperate zone.

Following the analysis conducted, it was concluded that most of the affected polygons had a predominantly coniferous vegetation composition (75\%), with slopes facing N, NW and W.

\subsection{Results validation}

Once the accuracy assessment has been set, the next step was the validation of results. Detecting forest surface changes using satellite imagery is a difficult task and requires validation using ground data. The validation was conducted based on disturbance data occurred in 2010 in the mountains area (data available on [70], referring to all types of disturbances, not only windthrows), on the cadastral forest plots for the two years (data available on [71], as well as on the aerial orthophotos of 2009 and the highresolution satellite imagery of 2010. For the final validation we used the change map obtained previously and we 


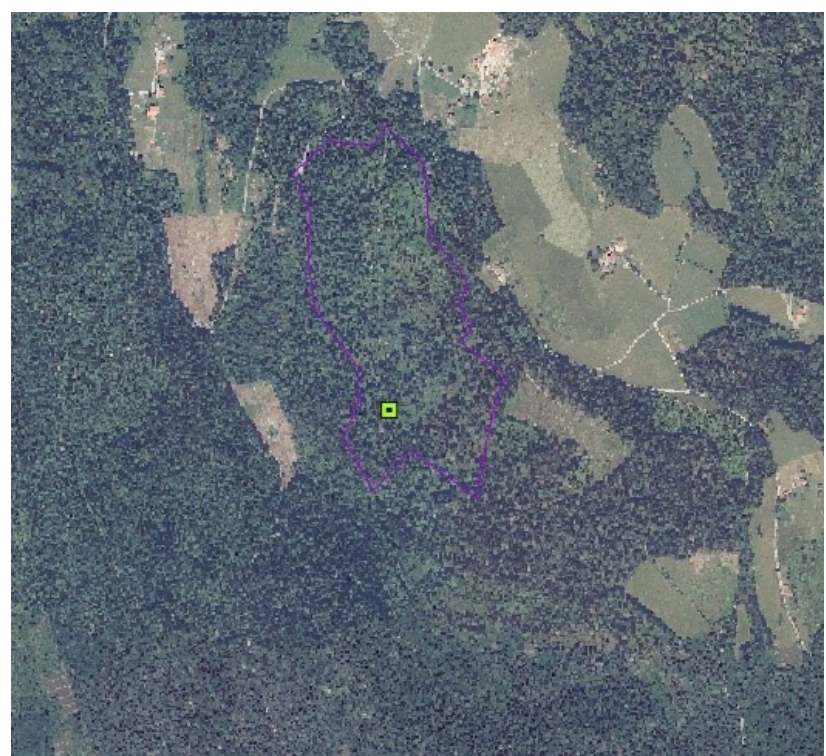

(a)

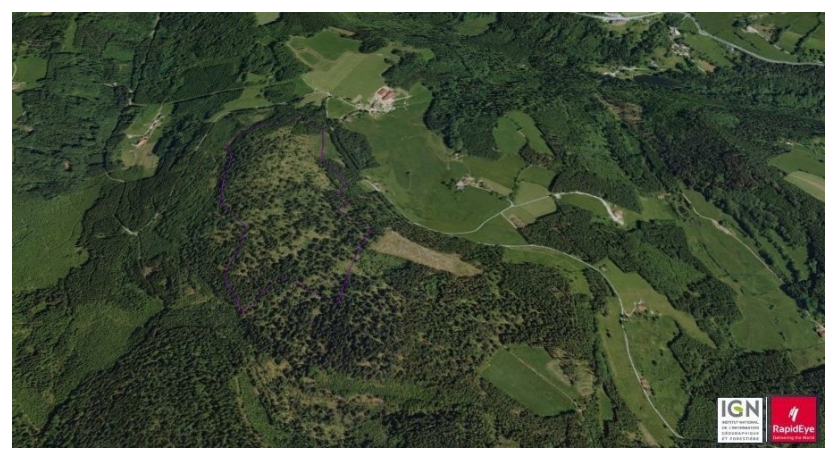

(b)

Figure 8: Overlapping a polygon extracted through the detection process with the 2009 orthophoto (a) and with the satellite image in 2010 (b)

combined it with data on disturbed forest areas, according to the French National Forest Inventory (IFN). The resulting polygons during the detection process were overlapped with the disturbed areas. Hence, we obtained a first validation of the results. Figure 7 highlights one of the polygons detected from the image processing, overlapped with the Landsat satellite image of 2009 (in Figure 7b), and the Landsat image in 2010, respectively (in Figure 7c).

Also, in order to obtain a picture of the "ground-truth", this polygon was overlapped with the aerial orthophoto of 2009, and with the 2010 satellite orthophoto (see Figure 8), thus achieving a new validation.

Another validation was carried out using highresolution satellite imagery available in Google Earth. For an easier interpretation of the effect of the Storm Xynthia, we zoomed out to a sample territory of $26.6 \mathrm{~km} \times 20.5 \mathrm{~km}$,

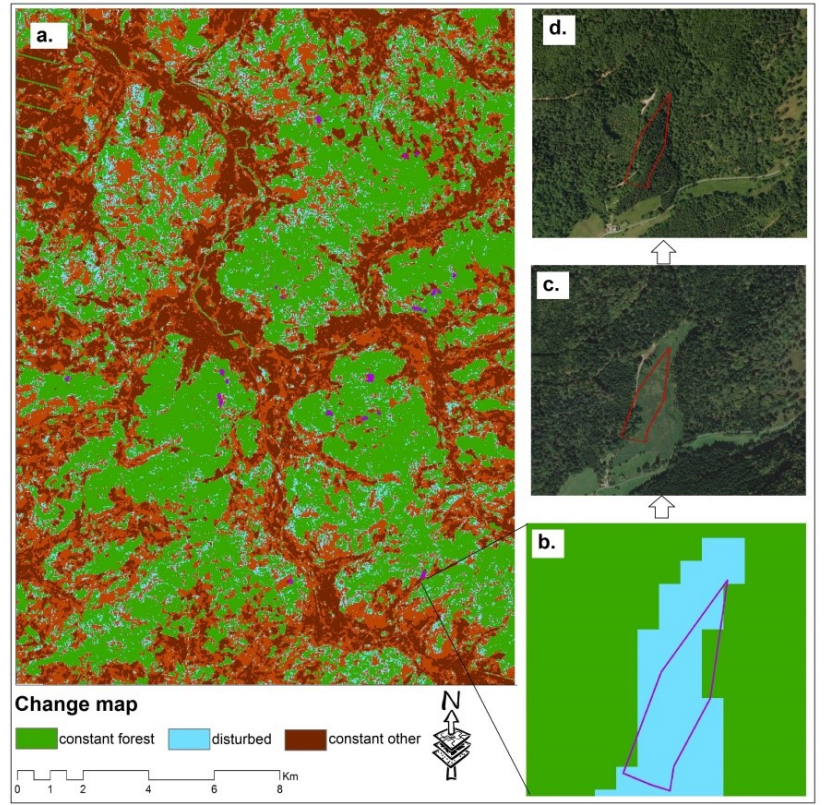

Figure 9: The forest change map overlaid with the polygons resulting from the detection process (a); zooming one polygon (b); the same polygon overlapped with the 2009 Google Earth satellite image (c) and from 2010, respectively (d)

i.e. 54,613 ha, with the Remiremont city at the centre (see Figure 9).

Hence, Figure 9(b) highlights another polygon obtained as a result of the disturbed areas detection process. This polygon is superimposed on the change map (in raster format). In the windthrows detection phase, raster data were used which were subsequently converted into vector data in order to overlap the final results. By converting these images, a comparison between the results detected on raster format (blue colour) and vector representation (purple polygon) was achieved. The geometric effect of this polygon obtained by switching from raster format to vector format suggests a possible underestimation of the actual area damaged by the wind. Figure 9(d) shows the image before the storm Xynthia, while Figure 9(c) illustrates the forest state after the storm Xynthia.

\section{Conclusions}

The tree windthrows caused by storms are much easier to detect by the authorities if they are contiguous, compared to the scattered or isolated ones. The scattered windthrows occur in the temperate zone at wind gusts of $100-140 \mathrm{~km} / \mathrm{h}$ and their areas range between a few tens of square meters and a few hectares, but they are very numerous (several hundreds in the wooded Vosges Mountains). For this rea- 
son, they are more difficult to detect, map and, obviously, it is much more difficult to characterize the extent of the damage. However, the detection of changes occurred as a result of the scattered windthrows, even if they are several hundreds, is also important in order to set the spatial and temporal rehabilitation and forest management trends. In this regard, this paper presents a rapid procedure for the detection of the scattered windthrows based on low cost images, knowing that certain sensors cannot be accessed without significant investments. Our application is based on the study of effects caused by the Storm Xynthia in the Vosges Mountains, on 28 February 2010.

The detection of areas damaged by the Storm Xynthia by applying the pixels delineation method based on the histogram enabled us to automatically delimit the forest pixels from the non-forest ones, thus reducing the working time. The Disturbance Index enabled the more accurate delineation of the affected areas.

The classification of the area into forest and non-forest increases the precision level for the detection of affected areas. The Tasselled Cap Transformation and the calculation of the Disturbance Index enable us to highlight the affected areas. The accuracy assessment of the results obtained for the change map was high ( $86 \%$ overall accuracy and the value of the Kappa coefficient was 0.84).

The results of this research highlight the usefulness of the Landsat satellite imagery, more easily to access than other types of images for the analysis and detection of windthrows.

It is worth mentioning that when detecting and assessing windthrows, the choice of the appropriate sensor will depend on the availability of data, cost, scale of the fragmented landscape and area of interest, because the high resolution imagery is not available globally, like Landsat data. If the exact small scale $(<0.5$ ha) delineation of the windthrow is needed, then the high-resolution imagery is suitable. But if the goal is to detect windthrows quickly, then the medium resolution data is more useful.

Acknowledgement: This research was supported by Centre de recherche en Géographie, LOTTER-EA7304, Université de Lorraine, Metz.

Conflict of Interests: The authors declare no conflict of interest

\section{References}

[1] Rauch E., Wind and storms. In Pfister C., Schellnhuber H., Rahmstorf S., Graßl H., (Eds.). Weather catastrophes and climate change. Is there still hope for us. In Munich, 2005, 132-143

[2] Bernardes S., Madden, M., Vegetation disturbance and recovery following a rare windthrow event in the Great Smoky Mountains National Park. In International Archives of the Photogrammetry, Remote Sensing and Spatial Information Sciences - ISPRS Archives, 2016; 41, 571-575

[3] Einzmann K., Immitzer M., Böck B., Bauer O., Schmit A., Atzberger C., Windthrow Detection in European Forests with Very HighResolution Optical Data. Forests, 2017, 8, doi:10.3390/f8010021

[4] Vernier F., L'ouragan Lothar, 26 Decembre 1999 effets et perspectives sur foret Lorraine. Bull. Acad. Soc. Lorraines. Sci., 2001, 40, 40-50

[5] Birot, Y., Landmann, G., Bonheme, I., La foret̂f face aux tempet̂es. Quae, 2009; ISBN 9782759203307

[6] Inventaire Forestiere National - IFN, Tempete Klaus du 24 Janvier 2009: 234000 hectares de forêt affectés à plu de 40\%, 42,5 millions de mètres cubes de dégât, 2009

[7] Pôle interrégional de la Santé des forêts. Bilan de la santé des forêts 2010 en Alsace, 2011

[8] Pôle interrégional de la Santé des forêts. Bilan de la santé des forêts 2010 en Lorraine, 2011

[9] Anziani A., Rapport d'information sur les conséquences de la tempête Xynthia. Session ordinaire du Sénat. 55410, 2010

[10] Hernu H., Kbaier R., Rochard J., Casteigts M., Furst X., Jullien B., Balay L.P., Guillet M., Rapport sur l'évaluation des dommages causés par la tempête Xynthia des 27 et 28 févri er 2010 à prendre en compte a titre du fonds de solidarité de l'union européenne. 2010

[11] Fédération Française des Sociétés d'Assurances / Groupement des entreprises mutuelles d'assurance - FFSA/GEMA, La tempête Xynthia du 28 février 2010 - Bilan chiffré au 31 décembre 2010. 2011

[12] Calvet F., Manable C., Rapport d'information sur Xynthia 5 ans après: pour une véritable culture du risque dans les territoires. 2015

[13] Office National des Forêts. Tempête Xynthia: des dégâts diffus en forêt. 2010

[14] Forêt Privée Française - FPF. Tempête Xynthia: des dégâts localise. Available online: https://www.foretpriveefrancaise.com/ actualite/voir/515/tempete-xynthia-des-degats-localises-enforet/n:1

[15] Papaik M.J., Canham C.D., Species resistance and community response to wind disturbance regimes in northern temperate forests. J. Ecol., 2006, 94, 1011-1026, doi:10.1111/j.13652745.2006.01153.x

[16] Bonan G.B., Forests and Climate Change: Forcings, Feedbacks, and the Climate Benefits of Forests. Science, 2008, 80, 14441449, doi:10.1126/science.1155121

[17] Klaus M., Holsten A., Hostert P., Kropp J.P., Integrated methodology to assess windthrow impacts on forest stands under climate change. For. Ecol. Manage. 2011, 261, 1799-1810, doi:10.1016/j.foreco.2011.02.002

[18] Merry K.L., Bettinger P., Hepinstall-Cymerman J., A prototype model for estiating the location of forest damage from tropical cyclones. Geogr. Tech., 2011, 6, 65-80 
[19] Thom D., Rammer W., Dirnböck T., Müller J., Kobler J., Katzensteiner K., Helm S., Seidl R., The impacts of climate change and disturbance on spatio-temporal trajectories of biodiversity in a temperate forest landscape. J. Appl. Ecol. 2017, 54, 28-38, doi:10.1111/1365-2664.12644.

[20] Seidl R., Schelhaas MJ., Rammer W., Verkerk P.J., Increasing forest disturbances in Europe and their impact on carbon storage. Nat. Clim. Chang. 2014, 4, 806-810, doi:10.1038/nclimate2318

[21] Merry K., Bettinger P., Siry J., Bowker J.M., Estimating urban forest carbon sequestration potential in the southern United States using current remote sensing imagery sources. Geogr. Tech. 2015, 10, 78-89

[22] Huang C., Yang W.L., Homer C., Zylstra G., Huang C., Yang W.L., Wylie B., Yang L., Homer C., Derivation of a tasselled cap transformation based on Landsat 7 at-satellite reflectance. Int. J. Remote Sens. 2002, 23, 1741-1748

[23] Healey S.P., Cohen W.B., Zhiqiang Y., Krankina O.N., Comparison of Tasseled Cap-based Landsat data structures for use in forest disturbance detection. Remote Sens. Environ. 2005, 97, 301-310 doi:10.1016/j.rse.2005.05.009

[24] Baumann M., Ozdogan M., Wolter P.T., Krylov A., Vladimirova N., Radeloff V.C., Landsat remote sensing of forest windfall disturbance. Remote Sens. Environ. 2014, 143, 171-179, doi:10.1016/j.rse.2013.12.020

[25] Jin S., Sader S.A., Comparison of time series tasseled cap wetness and the normalized difference moisture index in detecting forest disturbances. Remote Sens. Environ. 2005, 94, 364-372, doi:10.1016/J.RSE.2004.10.012

[26] Huang C., Goward S.N., Masek J.G., Thomas N., Zhu Z., Vogelmann J.E., An automated approach for reconstructing recent forest disturbance history using dense Landsat time series stacks. Remote Sens. Environ. 2010, 114, 183-198, doi:10.1016/j.rse.2009.08.017

[27] Zhu Z., Woodcock C.E., Olofsson P., Continuous monitoring of forest disturbance using all available Landsat imagery. Remote Sens. Environ. 2012, 122, 75-91, doi:10.1016/j.rse.2011.10.030

[28] Lambert J., Drenou C., Denux J.F., Balent G., Chéret V., Monitoring forest decline through remote sensing time series analysis. GIScience Remote Sens. 2013, 50, 437-457

[29] Stach N., Deshayes M., Durrieu S., Mapping clear-cutting in french forests by satellite remote sensing. In Proceedings of ForestSat, Håkan Olsson, Ed., 2005

[30] Huang C., Song K., Kim S., Townshend J. R.G.; Davis P., Masek J. G., Goward S. N., Use of a dark object concept and support vector machines to automate forest cover change analysis. Remote Sens. Environ. 2008, 112, 970-985, doi:10.1016/j.rse.2007.07.023

[31] Kennedy R.E., Yang Z., Cohen W.B., Pfaff E., Braaten J., Nelson P., Spatial and temporal patterns of forest disturbance and regrowth within the area of the Northwest Forest Plan. Remote Sens. Environ. 2012, 122, 117-133, doi:10.1016/j.rse.2011.09.024

[32] Stach N., Deshayes M., Le Toan T., Évaluation des dégâts de tempête par télédétection satellitaire: Aspects méthodologiques et opérationnels. 2002

[33] Inventaire Forestier National Cartographie des coupes rases des peuplements de pin maritime en Aquitaine par detection satellitaire. 2008

[34] Chéret V., Denux J.P., Gacherieu C., Ortisset J., Utilisation de séries temporelles d'images satellitales pour cartographier le dépérissement des boisements résineux du Sud Massif Central.
Rendez-vous Tech. - ONF 2010, 55-62

[35] Hussain M., Chen D., Cheng A., Wei H., Stanley D., Change detection from remotely sensed images: From pixel-based to objectbased approaches. ISPRS J. Photogramm. Remote Sens. 2013, 80, 91-106, doi:10.1016/j.isprsjprs.2013.03.006

[36] Bedacht E, Hofherr T., Winter Storm Xynthia in southwest Europe and Germany. Munich Re Top. Geo 2010, Catastroph, 18-22

[37] Bock J., Vinkler I., Duplat P., Renau J.P., Badeau V., Dupouey J.L., Stabilité au vent des hêtraies: les enseignements dela tempêtede1999. Forêt Entrep. 2004, 156, 34-38

[38] Meteo France. Available online: http://tempetes.meteo.fr/

[39] Schwarz M., Steinmeier C., Holecz F., Stebler O., Wagner H., Detection of Windthrow in Mountainous Regions with Different Remote Sensing Data and Classification Methods. Scand. J. For. Res. 2003, 18, 525-536, doi:10.1080/02827580310018023

[40] Goward S., Arvidson T., Williams D., Faundeen J., Irons J., Franks S., Historical Record of Landsat Global Coverage. Photogramm. Eng. Remote Sens. 2006, 72, 1155-1169, doi:10.14358/PERS.72.10.1155

[41] Vogelmann J.E., Gallant A.L., Shi H., Zhu Z., Perspectives on monitoring gradual change across the continuity of Landsat sensors using time-series data. Remote Sens. Environ. 2016, 185, 258270, doi:10.1016/j.rse.2016.02.060

[42] Turner W., Rondinini C., Pettorelli N., Mora B., Leidner A.K., Szantoi Z., Buchanan G., Dech S., Dwyer J., Herold M., Koh L.P., Leimgruber P., Taubenboeck H., Wegmann M., Wikelski M., Woodcock C., Free and open-access satellite data are key to biodiversity conservation. Biol. Conserv. 2015, 182, 173-176, doi:10.1016/j.biocon.2014.11.048

[43] Cohen W.B., Goward S.N., Landsat's role in ecological applications of remote sensing. Biosci. 2004, 54(6) 535-545

[44] Mukai Y., Hasegawa I., Extraction of damaged areas of windfall trees by typhoons using Landsat TM data. Int. J. Remote Sens. 2000, 21, 647-654, doi:10.1080/014311600210489

[45] Ramsey III, E.W., Hodgson M.E., Sapkota S.K., Nelson G.A., Forest impact estimated with NOAA AVHRR and Landsat TM data related to an empirical hurricane wind-field distribution. Remote Sens. Environmen 2001, 77, 279-292

[46] Jonikavičius D., Mozgeris G., Rapid assessment of wind stormcaused forest damage using satellite images and stand-wise forest inventory data. iForest, 2013, 6, 150, doi:10.3832/IFOR0715006

[47] Hermosilla T., Wulder M.A., White J.C., Coops N.C., Hobart G.W., Regional detection, characterization, and attribution of annual forest change from 1984 to 2012 using Landsat-derived time-series metrics. Remote Sens. Environ. 2015, 170, 121-132, doi:10.1016/j.rse.2015.09.004

[48] Malthus T.J., Suárez Mínguez J., Woodhouse I.H., Shaw D.T., Review of remote sensing in commercial forestry. 2002

[49] Suárez J.C., Ontiveros C., Smith S., Snape S., Use of airborne LiDAR and aerial photography in the estimation of individual tree heights in forestry. Comput. Geosci. 2005, 31, 253-262, doi:10.1016/j.cageo.2004.09.015

[50] Melesse A.M., Weng Q., Thenkabail P.S., Senay G.B., Remote Sensing Sensors and Applications in Environmental Resources Mapping and Modelling. Sensors (Basel). 2007, 7, 3209-3241, doi:10.3390/s7123209

[51] Gancz V., Apostol B., Petrila M., Lorent A., Detectarea cu ajutorul imaginilor satelitare a doborâturilor de vânt şi evaluarea efectelor acestora. Rev. Padurilor, 2010, 6, 30-37 
[52] Zhu Z., Woodcock C.E., Object-based cloud and cloud shadow detection in Landsat imagery. Remote Sens. Environ. 2012, 118, 83-94, doi:10.1016/J.RSE.2011.10.028

[53] Goodwin N.R., Collett L.J., Denham R.J., Flood N., Tindall D., Cloud and cloud shadow screening across Queensland, Australia: An automated method for Landsat TM/ETM+ time series. Remote Sens. Environ. 2013, 134, 50-65, doi:10.1016/j.rse.2013.02.019

[54] GloVis. Available online: https://glovis.usgs.gov/

[55] Chander G., Markham B.L., Barsi J.A., Revised Landsat-5 Thematic Mapper Radiometric Calibration. IEEE Geosci. Remote Sens. Lett. 2007, 4, doi:10.1109/LGRS.2007.898285

[56] Chander G., Markham B.L., Helder D.L., Summary of current radiometric calibration coefficients for Landsat MSS, TM, ETM+, and EO-1 ALI sensors. Remote Sens. Environ. 2009, 113, 893-903, doi:10.1016/J.RSE.2009.01.007

[57] Géoportail. Available online: https://www.geoportail.gouv.fr/

[58] IGN - Espace professionnel | L'information grandeur nature. Available online: http://professionnels.ign.fr/

[59] Kennedy R.E., Cohen W.B., Moisen G.G., Goward S.N., Wulder M., Powell S.L., Masek J.G., Huang C., Healey S.P., A sample design for Landsat-based estimation of national trends in forest disturbance and regrowth. In NASA Joint Workshop on Biodiversity, Terrestrial Ecology, and Related Applied Sciences, College Park, MD, 2006

[60] Kuemmerle T., Hostert P., Radeloff V.C., Perzanowski K., Kruhlov I., Post-socialist forest disturbance in the Carpathian border region of Poland, Slovakia, and Ukraine. Ecol. Appl. 2007, 17, 1279-95

[61] Masek J.G., Huang C., Wolfe R., Cohen W., Hall, F., Kutler J., Nelson P., North American forest disturbance mapped from a decadal Landsat record. Remote Sens. Environ. 2008, 112, 2914-2926, doi:10.1016/j.rse.2008.02.010

[62] Kuemmerle T., Chaskovskyy O., Knorn J., Radeloff V.C., Kruhlov I., Keeton W.S., Hostert P., Forest cover change and illegal logging in the Ukrainian Carpathians in the transition period from 1988 to 2007. Remote Sens. Environ. 2009, 113, 1194-1207, doi:10.1016/j.rse.2009.02.006

[63] Neigh C., Bolton D., Diabate M., Williams J., Carvalhais N., Neigh C.S.R., Bolton D.K., Diabate M., Williams. J.J., Carvalhais N., An Automated Approach to Map the History of Forest Disturbance from Insect Mortality and Harvest with Landsat Time-Series Data. Remote Sens. 2014, 6, 2782-2808, doi:10.3390/rs6042782

[64] Frantz D., Röder A., Udelhoven T., Schmidt M., Forest disturbance mapping using dense synthetic Landsat/MODIS time-series and permutation-based disturbance index detection. Remote Sens. 2016, 8, doi:10.3390/rs8040277

[65] Furtuna P., Temporal and spatial variation of forest coverage in Apuseni Natural Park, 2000-2014 perioad. Geogr. Tech. 2017, 12, 56, doi:10.21163/GT_2017.121.05

[66] Darwish A., Leukert K., Reinhardt W., Image segmentation for the purpose of object-based classification. In IGARSS, IEEE International Geoscience and Remote Sensing Symposium, 2003, 3, 2039-2041

[67] Vogelmann J.E., Gallant A.L., Shi H., Zhu Z., Perspectives on monitoring gradual change across the continuity of Landsat sensors using time-series data. Remote Sens. Environ. 2016, 185, 258270, doi:10.1016/J.RSE.2016.02.060

[68] Furtuna P., Haidu, I., Maier N., Synoptic Processes Generating Windthrow. A Case Study for Apuseni Mountains (Romania). Geogr. Tech. 2018, 13, 52-61, doi:10.21163/GT_2018.132.04
[69] Vorovencii I., Detection of environmental changes due to windthrows using Landsat 7 ETM+ satellite images. Environ. Eng. Manag. J. 2014, 13, 565-576

[70] Inventaire Forestier. Available online: https://inventaire-forest ier.ign.fr/

[71] Carmen - L'application cartographique au service des données environnementales. Available online: http://carmen.nature france.fr/

\section{Appendix A}

The largest polygon has an area of 13 ha (450-550 m altitude), East of the Grand-Soldat hamlet, Abreschviller village, department of Moselle. In the neighbouring Southern village of Saint-Quirin, the size of the second disturbed polygon is $9.2 \mathrm{ha}$ ( $450-330 \mathrm{~m}$ altitude). Also in Moselle there is a 7.7 ha polygon in the Northern Vosges Regional Natural Park, North of Baerenthal and a 7.9 hectare polygon SouthWest of Mouterhouse. In the department of Vosges there is a 6.1 hectare polygon South of Arrentès-de-Corcieux. In the department of Haut-Rhin in Alsace there is a 7.5 ha disturbed area North-West of Lake Grand Ballon, on the territory of the Lauteenbach-Zell village.

The analysis concluded that most of the affected polygons had predominantly coniferous vegetation (75\%), at an average altitude of $950 \mathrm{~m}$, with N-, NW- and W-facing slopes. Of the 257 polygons, only in 7 of them the disturbed areas exceed 5 hectares, but these are $51.12 \%$ of the total windthrow area. 56 polygons range from 1 to 5 ha and the remaining 194 polygons are under 1 ha. The smallest affected polygon detected by the methodology presented above and based on the limited data images approach is 0.09 ha. This is much better than the detection threshold based on 1 ha of satellite imagery that was used to assess the damage caused by the 1999 storms (83).

The large number of small polygons detected (194 polygons under $1 \mathrm{ha}$ ) comes as a result of the particularities of interaction between high wind speeds, over $130 \mathrm{~km} / \mathrm{h}$ and the relief characteristics of the Vosges Mountains. Generally, the affected polygons appear on the slopes facing the direction of the Storm Xynthia. At the escalation of the slopes, the speed of the wind gusts accelerated, leading to an effect similar to a buoyant force, resulting in a greater pressure exerted on the forest cover area. 